\title{
Risus mediaevalis. Laughter in medieval literature and art, edited by Herman Braet, Guido Latré, Werner Verbeke
}

\section{G. Matteo Roccati}

\section{(2) OpenEdition}

Journals

Édition électronique

URL : http://journals.openedition.org/studifrancesi/34212

DOI : 10.4000/studifrancesi.34212

ISSN : 2421-5856

Éditeur

Rosenberg \& Sellier

Édition imprimée

Date de publication : 1 novembre 2005

Pagination : 385

ISSN : 0039-2944

\section{Référence électronique}

G. Matteo Roccati, «Risus mediaevalis. Laughter in medieval literature and art, edited by Herman Braet, Guido Latré, Werner Verbeke », Studi Francesi [En ligne], 146 (XLIX | II) | 2005, mis en ligne le 30 novembre 2015, consulté le 21 avril 2021. URL : http://journals.openedition.org/studifrancesi/34212 ; DOI : https://doi.org/10.4000/studifrancesi.34212

Ce document a été généré automatiquement le 21 avril 2021.

\section{cc) (†) $\odot$}

Studi Francesi è distribuita con Licenza Creative Commons Attribuzione - Non commerciale - Non opere derivate 4.0 Internazionale. 


\title{
Risus mediaevalis. Laughter in medieval literature and art, edited by Herman Braet, Guido Latré, Werner Verbeke
}

\author{
G. Matteo Roccati
}

\section{RÉFÉRENCE}

Risus mediaevalis. Laughter in medieval literature and art, edited by Herman BRAET, Guido LATRÉ, Werner VERBEKE, Leuven, Leuven University Press ("Mediaevalia Lovaniensia Series I / Studia", XXX), 2003, pp. 224.

1 Un colloque sur le récit comique au Moyen Age, tenu en mars 1998, est à l'origine du volume. Je signale ici les contributions concernant l'aire française (les plus nombreuses) et celles d'intérêt général. Johan VERBERCKMOES, What about Medieval Humour? Some Historiography, pp. 1-9, donne un aperçu de la problématique dans l'historiographie du XXe siècle. Derek BREWER, The Comedy of Corpses in Medieval Comic Tales, pp. 11-29, sur le thème du cadavre, avec quelques références à des textes français. Herman BRAET, Entre folie et raison : les drôleries du ms. B.N., fr. 25526, pp. 43-74, étude du décor marginal de ce manuscrit, considéré comme exemplaire, dans le but de saisir la logique de ce genre de décoration. Philippe MENARD, Les illustrations marginales du 'Roman d'Alexandre' (Oxford, Bodleian Library, Bodley 264), pp.75-118, classe les marginalia en fonction des sujets (vie quotidienne, jeux, images comiques) et souligne leur autonomie par rapport au texte et aux grandes miniatures. Jean BATANY, Quelques effets burlesques dans le 'Livre des Manières', pp. 119-128, détaille la recherche d'effets burlesques dans le «tableau des devoirs et des vices des différentes catégories sociales» (pp. 119-120) qu'est le Livre d'Etienne de Fougères (vers 1170). Rosanna BRUSEGAN, La plaisanterie dans le 'Lai de Nabaret', pp.129-141, commente les éléments du lai en recourant à plusieurs parallèles littéraires. Jean SUBRENAT, Fabliau et satire cléricale : la spécificité de 'Frere Denise' par Rutebeuf, pp.143-153, met en lumière dans le texte les caractères particuliers de la 
satire visant les Frères Mineurs. Tony HunT, Les 'us' des femmes et la 'clergie' dans 'Richeut', pp. 155-172, souligne la cohérence de l'œuvre et examine les caractères du comique qui porte sur « les trois clés de voûte de la culture courtoise : la courtoisie (...), la chevalerie (...) et la clergie» (p. 158). Norris J. LACY, Halfway to Quixote: Humour in 'Blandin de Cornoalha', pp. 173-180, à propos de Blandin de Cornouaille. Gilbert TournoY, Footsteps in the Snow: A Latin Tale from Charlemagne to Justus Lipsius and Beyond, pp. 207-217, sur la fortune de l'anecdote de la fille de Charlemagne portant son ami sur ses épaules pour éviter qu'il laisse des traces dans la neige. Le volume est complété par l'Index codicum manu scriptorum (p. 219) et l'Index auctorum operumque (pp. 221-223). 